Original Research

\title{
Preliminary Results of Applying 2D Hydrodynamic Models of Water Reservoirs to Identify their Ecological Potential
}

\author{
Pawel S. Hachaj \\ Institute of Water Engineering and Water Management, Kraków University of Technology, Kraków, Poland
}

Received: 4 September 2017

Accepted: 16 October 2017

\begin{abstract}
In order to asses and evaluate the ecological potential of dammed storage reservoirs we need insight into the spatial structure of their hydrodynamics. This structure is influenced by a number of internal and external factors that may depend on each other. To understand these factors better it is necessary to find dependencies between them, to develop methods and techniques of building scenarios that integrate spatial and temporal features of the subsequent hydrodynamic "states" of the reservoir. These scenarios are meant to be the physical base for any subsequent biochemical water quality assessment within the given reservoir. This article presents the basics of the proposed techniques along with their applications on two multi-purpose storage reservoirs located in southern Poland within the upper Vistula River catchment: Dobczyce and Goczałkowice. Preparing the observational data for their use in numerical models and the application of these models and a few preliminary results obtained for real-life issues regarding the chosen reservoirs are presented and discussed. The possibilities of generalizing the proposed techniques toward a methodology of hydrodynamic conditions assessment for improving the ecologic potential of dammed reservoirs is also briefly outlined.
\end{abstract}

Keywords: hydrodynamics of storage reservoir, water management, water body ecological potential, conceptual approach, numerical model

\section{Introduction}

The subject of water dynamics in storage reservoirs is still not a well-known area of our knowledge. Those water bodies are also referred to as "dam lakes," "retention lakes," "retention reservoirs," and other similar terms. They are created by building a dam at a chosen river cross-section, causing the water level to

*e-mail: pawel.hachaj@iigw.pk.edu.pl rise and eventually forming a lake that the river flows through.

Artificial storage lakes have usually complex bathymetry with depths located near the dam position and shallows in their rear part. Due to their artificial nature and the tasks assigned to them they also have complex hydrology for main water balance. The main parameters from this point of view are: the water surface level near dam and indirect assessment of inflow/outflow at the main sources. This approach is justified by the need to control the outflow from the water reservoir based on its control rules. 
Yet in order to asses and evaluate the ecological potential of such reservoirs, insight into the spatial structure of their hydrodynamics is necessary. This structure is influenced by a number of internal and external factors that may depend on each other. Among such factors the following should be mentioned:

- Geometry and roughness of the reservoir bed, possibly containing the remnants of flooded structures including old river beds and shafts.

- Locations and discharge characteristics of the inflows and outflows of the reservoir.

- Meteorological condition, especially wind velocity and direction, plus air temperature and precipitation.

The relationships between these parameters is nontrivial and their total impact is unsteady and subject to seasonal changes. For example, they may have an effect on the vertical temperature distribution within the reservoir, resulting in the seasonal appearance of a thermocline that influences the water velocity field.

To analyze and evaluate the ecological potential of a storage reservoir one may use appropriate $2 \mathrm{D}$ or 3D computational models. They are able to calculate the water velocity fields in the reservoir working under certain (given) conditions. But it is not enough to asses just a set of more or less ephemeral velocity fields; it is necessary to find dependencies between them, to develop methods and techniques of building scenarios out of them. Such scenarios should:

- Group external influences.

- Integrate internal couplings and feedbacks.

- Allow identification of currents, stagnant areas, and basins of different flow characteristics.

- Allow determining the possible ways and timing of dissolved and suspended constituents that influence the biochemical quality of the water body.

- Allow evaluation of condition for persistence of nearstationary states of the reservoir as well as transitions between such states, as they are essential for determining the ecological potential of the reservoir.

The mentioned approach is supposed to be applied primarily to distinctive Polish dam reservoirs that are usually shallow but of complex shoreline and which are exposed to ever-changing hydrometeorologic conditions. This is especially important nowadays: for some reservoirs (especially water supply ones) possible changes in their use are being discussed. From this point of view the discharge rates are close in value to the appropriate average annual discharge (AAD).

This article concludes the first phase of the analysis project. The main aim was to find a generic methodology that can be applied to identify states and scenarios for a storage reservoir in question. As test objects, two reservoirs in the southern Poland were selected:

- The Dobczyce Reservoir on the Dunajec River - the water supply inlet located there is the primary source of drinking water for the city of Kraków [1-3].

- The Goczałkowice Reservoir on the upper Vistula River - the water supply for the Upper Silesia metropolitan area [4].
The quantitative analyses were performed using three 2D depth-averaged models belonging to the surface water modeling solution (SMS) [5] package: FESWMS [6], RMA [7], and AdH [8-9]. The models were calibrated for proper simulations of hydrodynamics of the chosen reservoirs with their water surface level close to their normal values, in the regime of low to medium discharges (close to their AAD-s). They have been tested as appropriate for this purpose [10-15].

The chapters that follow outline:

- The basics of applying the models on the reservoirs on the example of applying the AdH model on the Dobczyce Reservoir.

- The approach to the selection of hydrometeorologic parameters from the data cloud generated by high resolution measurement posts, along with the example of choosing typical wind parameters for the Goczałkowice Reservoir.

- The results of selection of the integrated scenarios for identifying currents and stagnant basins on the example of the Goczałkowice Reservoir.

- The results of the analysis of the pollution constituents tracking and timing as a means of water supply inlet protection on the example of the Dobczyce Reservoir.

- The conclusions about possibilities of generalizing the proposed techniques toward a methodology of hydrodynamic conditions assessment for improving the ecological potential of reservoirs.

\section{Applying the Models}

In order to calculate the velocity fields within the reservoirs, 3 models belonging to the SMS package were chosen:

- FESWMS (best for particle tracking purposes).

- RMA (best for simulations that involve dispersion).

- AdH (best for unsteady discharge conditions).

All three models are 2-dimentional depth-averaged hydrodynamic finite element models based on the mass and momentum conservation equations.

The basic input data for the models include: bed shape (bathymetry), bed friction parameters, initial water surface level, water parameters (density, viscosity), and inflows and outflows (constant, timedependent, or surface level dependent). The above may be extended by case-specific conditions, including wind conditions, atmospheric pressure changes, Coriolis effect, fixed ceilings (e.g., bridges), and parameters of the ice layer.

The main result of the model run is a twodimensional planar field of the average horizontal velocity of water. This field may be static or timedependent according to the conditions imposed upon the domain. Some additional obtainable features include drying and wetting of bed regions, particle tracking, and basic sediment transport.

In order to obtain the solution the models use conservation equations for both mass (continuity 
equation) and momentum. The following subsections present the appropriate formulas. The following continuity equations are in use for determining the cross-section area and discharge in any given section. (Note: equations 1 to 4 are the ones used by the $\mathrm{AdH}$ model. To keep the article compact the corresponding equations used by the FESWMS and RMA models are omitted. For computational details about those models refer to [6] and [7].)

$$
\begin{gathered}
A=\int_{B} H d B \\
Q=\int_{B} U \cdot H d B
\end{gathered}
$$

...where $A$ is cross-section area, $Q$ is discharge, $U$ is vertically averaged velocity of the flow, $H$ is local water depth, and $B$ is section width.

The mass conservation equation on any given planar element is:

$$
\frac{\partial \mathrm{H}}{\partial \mathrm{t}}+\frac{\partial\left(\mathrm{Hv}_{\mathrm{x}}\right)}{\partial \mathrm{x}}+\frac{\partial\left(\mathrm{Hv}_{\mathrm{y}}\right)}{\partial \mathrm{y}}=0
$$

...where $v_{x}$ and $v_{y}$ are velocity components in $x$ and $y$ directions, respectively.

The AdH model uses two-dimensional momentum conservation equations. The equation for the $x$ direction is as follows:

$$
\begin{aligned}
& \frac{\partial v_{x}}{\partial t}+v_{x} \frac{\partial v_{x}}{\partial x}+v_{y} \frac{\partial v_{x}}{\partial y}+g \frac{\partial \zeta}{\partial x}+g v_{x} \frac{\sqrt{v_{x}^{2}+v_{y}^{2}}}{C^{2} H}+ \\
& +g v_{x} T_{w x}-v_{x}\left(\frac{\partial^{2} v_{x}}{\partial x^{2}}+\frac{\partial^{2} v_{x}}{\partial y^{2}}\right)+\frac{1}{\rho} \frac{\partial p}{\partial x}=F_{x}
\end{aligned}
$$

...where: $g$ is gravitational acceleration, $\zeta$ is bed level, $C$ is Chezy coefficient, $T_{w x}$ is Wind stress coefficient (dependant on relative wind velocity and air density), $p$ is external pressure, and $\partial$ is water density.

The equation for the $y$ direction is analogous.

These equations may be both simplified and/or supplemented if necessary. For standard calculations of water flow in retention reservoirs the external pressure, treated as the atmospheric one, is considered to be constant. This allows omitting the appropriate term and simplifying the equation. Additional forces caused, e.g., by the coriolis effect or ice may be added to these equations if desired.

The models solve their equations on finite element meshes. The meshes contain several thousand elements that may be either only triangular or both triangular and quadrilateral. Fig. 1 presents one of the meshes built for the Dobczyce Reservoir for use with the AdH model. The meshes are being constructed semi-automatically within the SMS environment so that the shapes and sizes

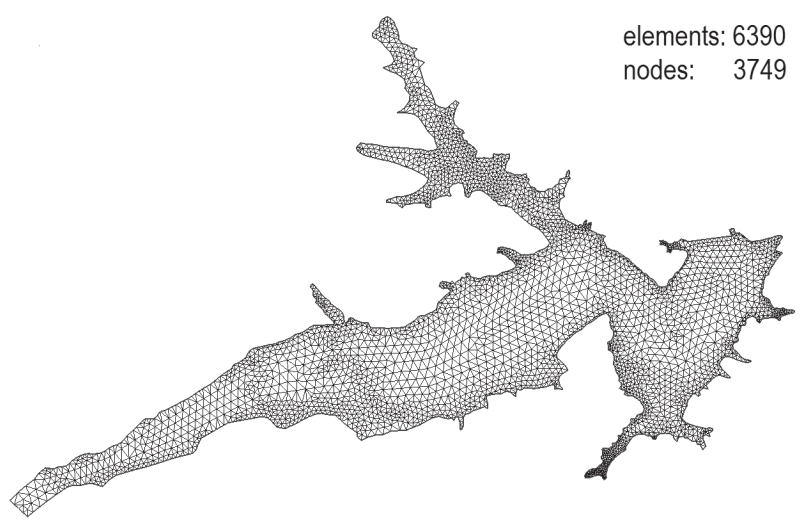

Fig. 1. Sample computational mesh for Dobczyce reservoir.

of elements follow the features of the reservoir beds according to the bathymetric maps of the reservoirs.

The parameters of the models are being adjusted to calibrate the results in accordance with real-life observational data regarding the reservoirs in question. Special caution and attention should be paid to the parameters responsible for friction forces - namely bed roughness and turbulent viscosity parameters. In order to properly reconstruct well-localized currents that appear in actual reservoirs, an iterative procedure of viscosity adjustment needed to be applied as described in [16].

\section{Selecting Hydrometeorologic Parameters}

The main hydrometeorologic parameters that shape the velocity fields in storage reservoirs are: total discharge, water surface elevation level, and wind velocity.

As for the discharge: low-to-medium discharge regimes were taken into account as present during most of the time and thus having long-lasting impact on the water dynamics and subsequently its biochemical quality. Both the considered reservoirs, Dobczyce and Goczałkowice, can be treated as having one primary and one secondary inflow and one primary and one secondary outflow. For the main outflows they are located by the appropriate dams, while the secondary outflows are located at the water supply inlets. The main inflow for Dobczyce is the Raba River flowing in from the west, the secondary one is Wolnica Creek entering the northern bay of the reservoir. The main inflow for Goczałkowice is the Vistula River flowing in from the west, and the secondary is Bajerka Creek entering the northern bay of the reservoir. The AAD values for all the main inflows and outflows are close to $10 \mathrm{~m}^{3} / \mathrm{s}$, for the secondary inflows are below $1 \mathrm{~m}^{3} / \mathrm{s}$, and for the secondary outflows they are about $2 \mathrm{~m}^{3} / \mathrm{s}$. Values of the mentioned orders of magnitude were taken as input to the simulational analysis.

It should be mentioned that total inflow may be different than total outflow; if so, this results in filling up or emptying the reservoirs. In principle this leads to 


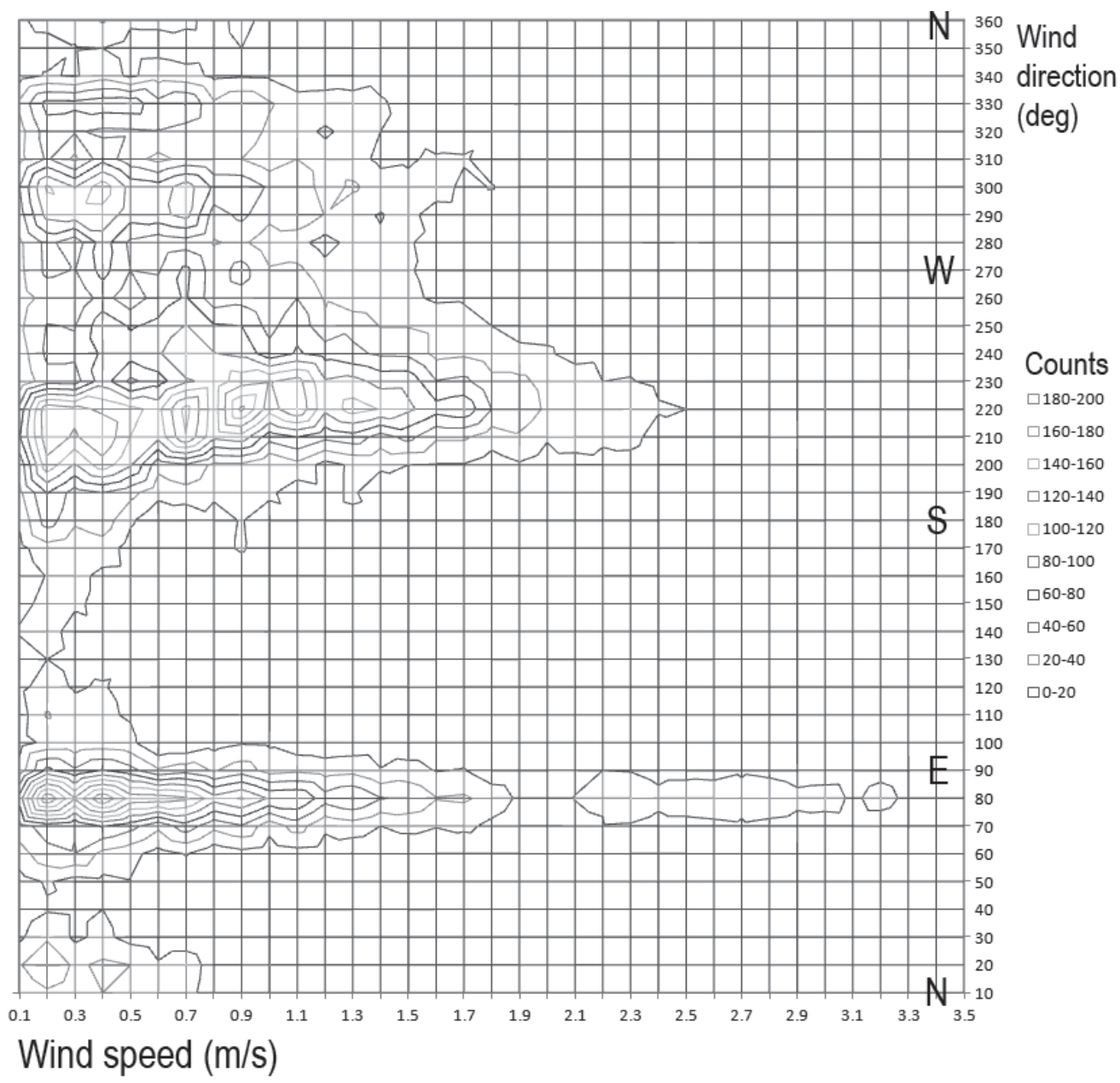

Fig. 2. Wind direction versus wind speed as measured for Goczałkowice Reservoir (2D histogram).

changes in the water surface elevation, which the models should cope with, and they did. It is noteworthy that the water surface elevation changes for the considered discharge surpluses, and deficiencies were small enough (millimeters to centimeters) not to change the shape of the reservoir shorelines in any quantifiable way.

The data for the wind were taken from highresolution meteorological stations that were recording both components of the wind velocity - its speed and angle - in the 24/7 regime every 10 minutes. This resulted in producing large sets of temporal wind data. The resolution for wind speed was $0.1 \mathrm{~m} / \mathrm{s}$ and the resolution for the wind angle was 10 degrees. Before being used, the wind-related data needed to be checked for consistency. Indeed, the stations had periods of various malfunctions. While the periods of being off can be easily recognized, others (like jamming of one or more of the gauges, which happened a number of times) required a cross-check analysis between the data recorded at several posts. Finally, a set of over 25,000 verified non-zero measurements was established as a representative yearly sample of wind velocity.

The size of the sample allowed for a more detailed wind assessment than one offered by a traditional wind rose approach. While the latter offers just a few selected directions of the wind along with the average value of the wind speed for the given direction, this time it was possible to make a 2-dimensional analysis of the speed/ direction pairs.

The resulting 2D histogram for the Goczałkowice Reservoir is shown in Fig. 2. One can easily see that the most common wind direction is 220 degrees, which corresponds to the southwestern direction. Although the most probable wind speed for this angle is up to about $1.5 \mathrm{~m} / \mathrm{s}$, the 20 counts contour extends to $2.5 \mathrm{~m} / \mathrm{s}$. Then there is a broad range of roughly western winds with another maximum of 300 degrees, which corresponds to the WxNW direction. Southeastern and north- to northeastern wind happens rarely. Yet eastern winds (80 degrees) do happen; although they are less common than (south-)western ones, they can be strong. Their velocity is usually up to $1.1 \mathrm{~m} / \mathrm{s}$, but the 20 counts contour extends to more than $3 \mathrm{~m} / \mathrm{s}$. The topmost speed peak $(13 \mathrm{~m} / \mathrm{s})$ has been recorded together with the angle of 80 degrees.

This justified taking the following wind conditions as "normal" for further analyses of Goczałkowice Reservoir hydrodynamics:

- No wind.

- Wind of 220 degrees up to $2.5 \mathrm{~m} / \mathrm{s}$. 


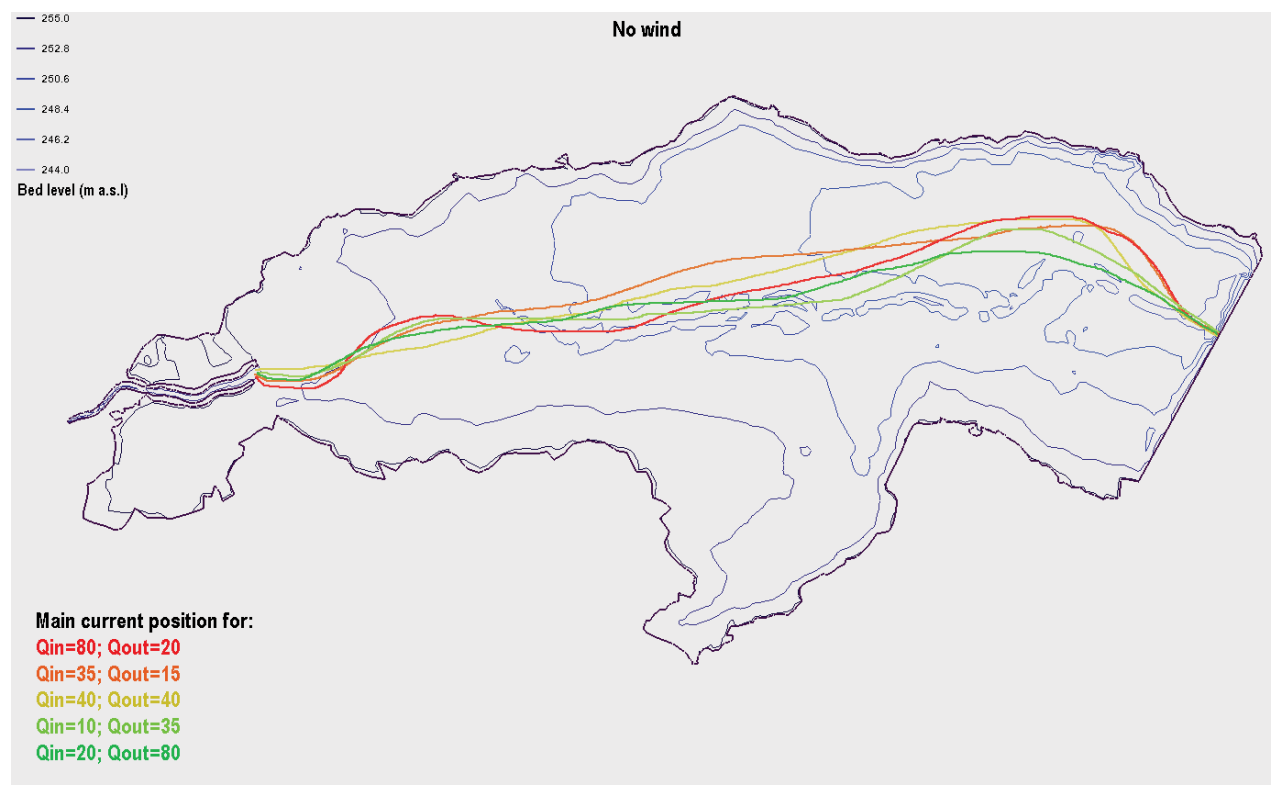

Fig. 3. Main current shape in Goczałkowice Reservoir for different inflow, Qin $\left(\mathrm{m}^{3} / \mathrm{s}\right)$, and outflow, Qout $\left(\mathrm{m}^{3} / \mathrm{s}\right)$ values and for windless weather.

- Wind of 300 degrees up to $1.5 \mathrm{~m} / \mathrm{s}$.

- Wind of 80 degrees up to $3 \mathrm{~m} / \mathrm{s}$.

The Dobczyce Reservoir, as deeper and having a smaller surface area than Goczałkowice Reservoir, should be in principle less susceptible to wind conditions as a parameter shaping its hydrodynamics. Yet even in this case the wind turned out - together with the discharge - to be the main factor responsible for the water velocity field in the reservoir. Along with similar characteristic discharges discussed above, this made possible the reuse analysis schemes tried on one of these reservoirs being applied to another one with only small adjustments.

\section{Selecting the Integrated Scenarios}

In order to assess the ecological potential of a storage reservoir, one needs to select the water currents as well as basins of the reservoir that share common dynamic properties. They can serve as the base for further biomass balance analysis, and the study of biological conditions changes in space and time. This kind of assessment should finally predict the evolution of dynamic and biochemical conditions along with the seasons of the year. Ultimately these assessments should include linking the climate characteristics with the dynamic structures within the reservoir in proper time intervals for the existence of biological forms. Such integrated scenarios should also include transitional forms from one reservoir state to another with respect to all considered dynamic and biochemical factors. The next step toward this goal is to develop a methodology of distinguishing hydrodynamic states of the reservoir and then to build dynamic scenarios out of them as described below.
Having the hydrometeorologic parameters sorted out, it becomes possible to perform a comprehensive set of simulations - one that covers all the common combinations of these parameters and those of the uncommon combinations that are interesting from either scientific or utilitarian purposes. The results of the simulations are velocity fields containing a lot of information. Again, somehow similarly to the wind data issue discussed above, the abundance of the data is a difficulty here. It is needed to extract meaningful "signal" information that improves our understanding of the processes within the reservoir, from the "noise" data representing immeasurable changes, insignificant epiphenomena, or even modeling errors.

In order to do this a concept of "observables" has been introduced. The term "an observable", borrowed from quantum mechanics, means: A feature of the system (here: a storage reservoir) that can actually be observed and feasibly measured in practice. As such it can be compared between several model run results as well as between model calculation outcome and reallife measurement. For example the shape of the current within the reservoir is an observable, as are the shapes of stagnant areas or the current velocity (if high enough). On the contrary, the depth-averaged planar velocity field is not an observable, neither is it the vertical component of the velocity in an arbitrary point.

By comparing the results of the calibrated model runs with each other, one can select and distinguish the system parameters responsible for changes of the considered observables. For example, one of the primary observables is the presence and shape of the main current within the reservoir. As shown in Fig. 3, this observable for the Goczałkowice Reservoir exhibits little change versus the changes in the main inflow and main 


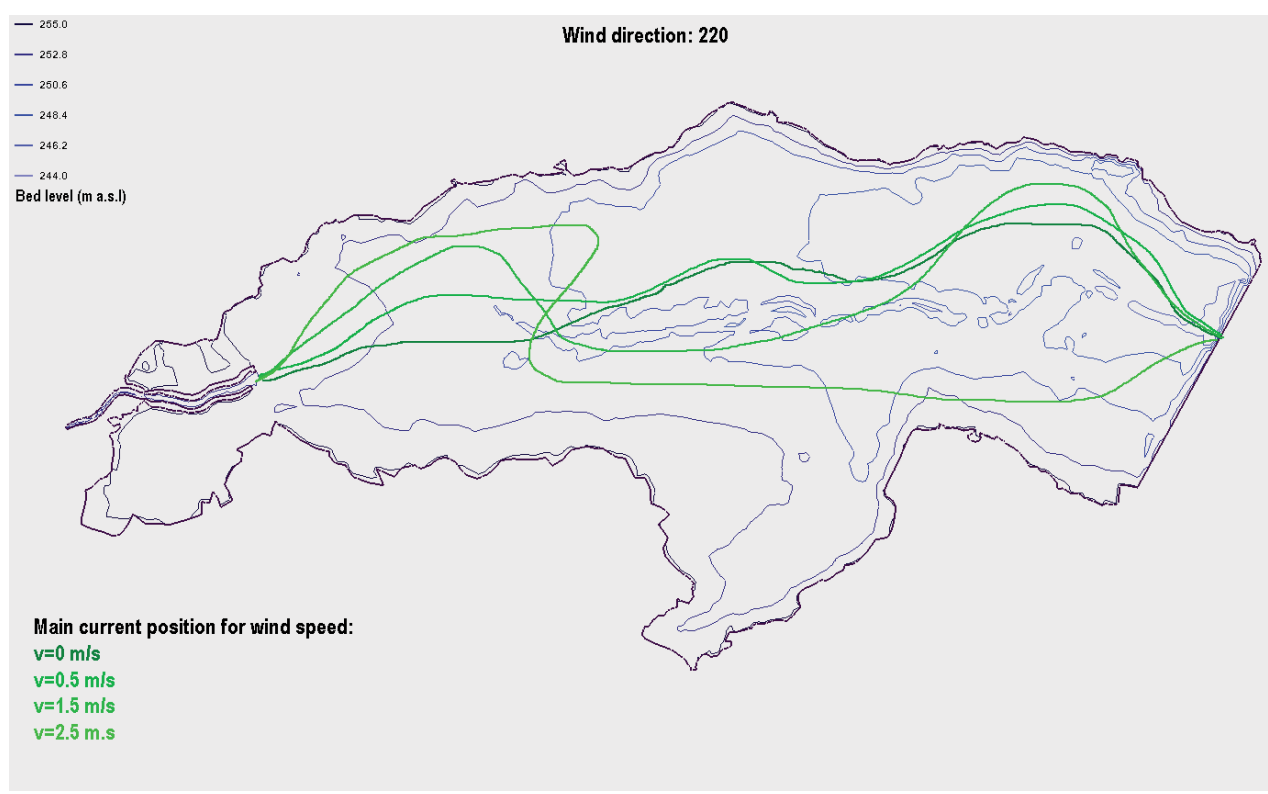

Fig. 4. Main current shape in Goczałkowice Reservoir for stationary flow $Q=7 \mathrm{~m}^{3} / \mathrm{s}$ and different speeds of the southwestern (220 degrees) wind.

outflow parameters in the absence of wind. On the other hand, the same observable proves to be susceptible to the changes of the wind parameter as presented in Fig. 4.

The dependence between a parameter and an observable may be either gradual or threshold (chaotic). In the first case small changes of the parameter cause a proportional change of the observable (for example the curvature of a given current bend grows with the discharge). In the second case the observable is stable with respect to the changes of a parameter up to some threshold value, where it changes significantly (e.g., when the wind is stronger than the threshold value a vortex appears in a previously stagnant region, or the current "jumps" from the vicinity of the southern bank to the northern one). Mixed cases are also possible.

The next step is preparing maps of key features (observables) of the reservoirs for miscellaneous values and/or ranges of the input parameter. Fig. 5 presents such a map made for the Goczałkowice Reservoir prepared for the stationary state of the total discharge of $7 \mathrm{~m}^{3} / \mathrm{s}$ and southwestern wind of $1.5 \mathrm{~m} / \mathrm{s}$. The analysis described above indicated that this map is also valid for the discharge in the range $4-12 \mathrm{~m}^{3} / \mathrm{s}$ and the wind velocity within the moderate southwestern maximum

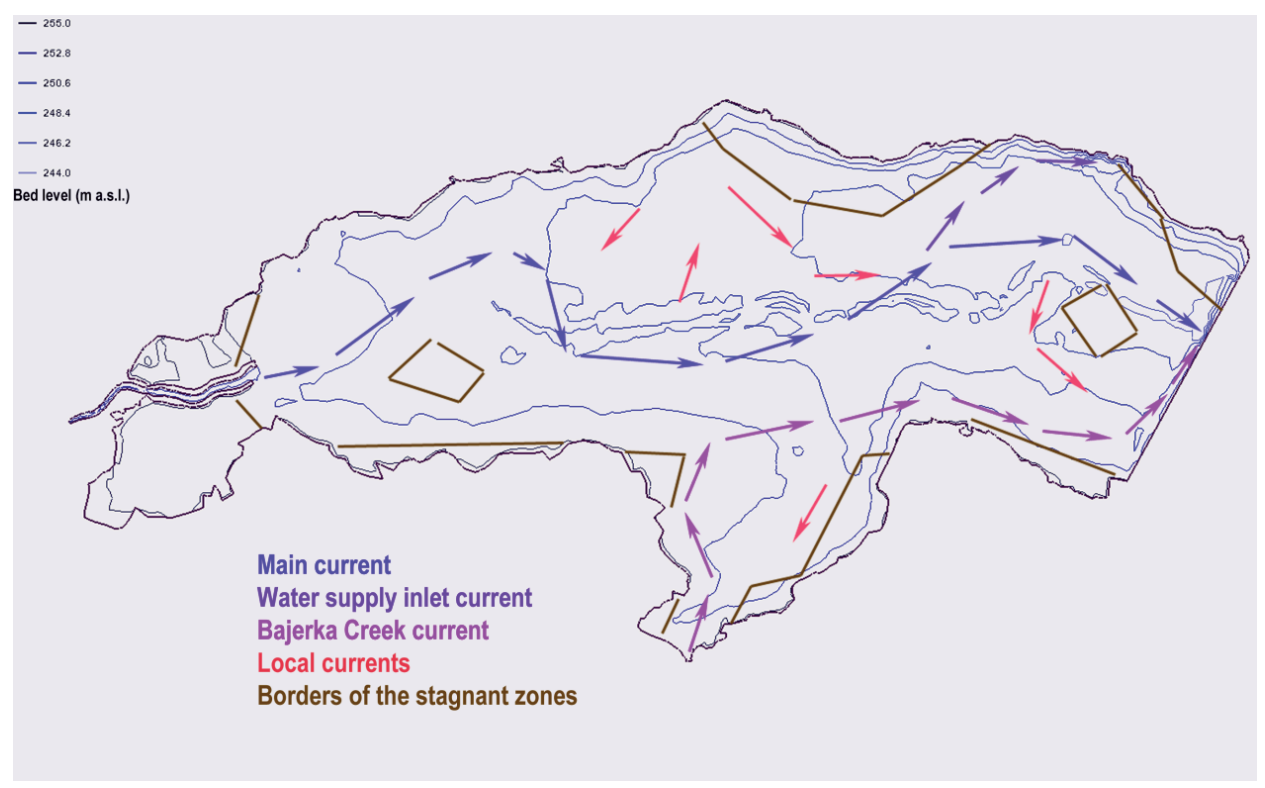

Fig. 5. Currents and stagnant areas in Goczałkowice Reservoir for stationary flow $\mathrm{Q}=7 \mathrm{~m}^{3} / \mathrm{s}$ and moderate southwestern wind ( $\mathrm{v}=1.5$ $\mathrm{m} / \mathrm{s}$, direction 220 degrees). 
visible in Fig. 2, i.e., speed in the range $0.9-1.7 \mathrm{~m} / \mathrm{s}$ and angle in the range $205-235^{\circ}$. Visible features include the following:

- The main current flows closely to the old Vistula River bed (still visible on the bathymetric map), but not exactly along it.

- The side current from Bajerka Creek joins the main one effectively at the reservoir outflow.

- The main current forks twice: first creating a new current toward the water supply inlet, second forming a local current that joins the one from the Bajerka.

- The stagnant areas are located:

- In the western backwater basins (these remain stagnant for most standard conditions imposed on the reservoir).

- Along the banks, as a number of relatively narrow stripes.

- In the shallow region southwards to the bend of the main current (this one seems to be separated from the bank stagnant zone by the intermediate area, where the water may flow either eastward or westward, seemingly randomly).

- Between the Bajerka current and the main one.

These observables maps representing various states of the reservoir may then be used for the analyzing the scenario of state changes. Such scenarios can be treated as temporal sequences (chains) of states of the object. Analysis of these scenarios can be a useful tool for assessing the ecological potential of the reservoir. For example: The stagnant areas are the ones where eutrophication likely occurs. So let us take a scenario involving three states:

- A long-lasting state with a stagnant area somewhere far from the dam; eutrophication happens there.

- A short-lived state with a strong current crossing the previously stagnant area that flushes away eutrophic water elsewhere.

- A long-lasting state similar to the first one, but with a cloud of eutrophic water located in the area of one of the currents.

Such a scenario would result in a bubble of eutrophic water migrating within the reservoir. Indeed, this phenomenon has been observed on Goczałkowice Lake, and is described by the reservoir staff as clouds of green water floating along the reservoir without significant changes in size.

\section{Pollution Constituents Tracking and Timing}

Assessing the ecological potential of the dammed reservoir refers to long time scales and focuses on water body quality regarding its biological perspectives. From the utilitarian point of view there exists another, shorter time scale regarding the water quality in a given reservoir or in its distinguished parts (basins). The physical, chemical, and biological water quality should be taken into account in the context of protection of the water supply inlets present within the water body. This includes:

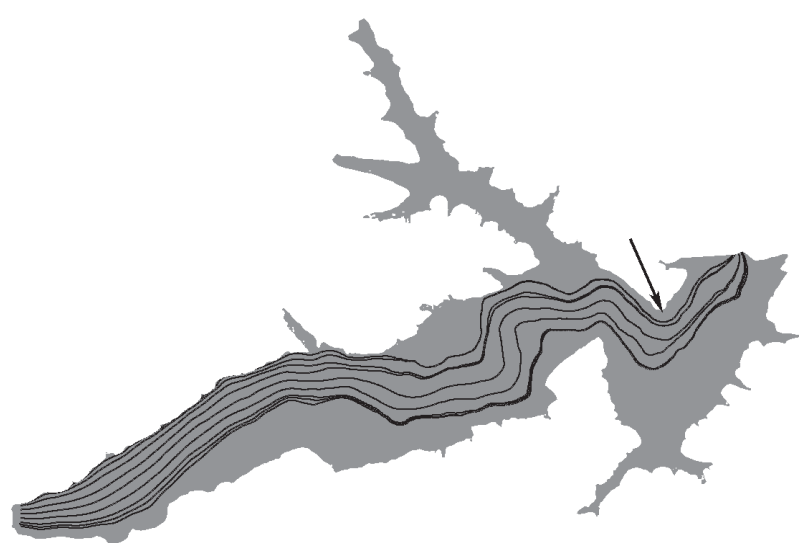

Fig. 6. Particle tracking for Dobczyce Reservoir from the Raba River inlet to the dam outlet (average annual discharge, no wind); the arrow denotes the position of the water supply inlet; the current-driven particles reach the inlet about 3 days after entering the reservoir.

- Preventive means, especially establishing the water supply protection areas; this applies in particular to "zone A," for which the time of possible pollution influx is shorter than stated in the appropriate regulations.

- Contingency plans for the circumstances of a direct threat for the water supply inlet by harmful substances carried by water.

Among the methods for achieving the stated goals there is a place for transitory scenario analysis - an approach to model the transport of possible pollutants using Lagrangian tracking of the "pilot" particles combined with diffusive dispersion of the active constituent. The role of such dynamic, transitory scenarios is coupled with the role of ecological potential scenarios described in the previous chapter. Protecting and maintaining the quality of a dammed reservoir requires integrating both short- and long-term approaches.

A set of transitory scenarios has been prepared to determine potential threats for the water supply inlet located on Dobczyce Reservoir. The main aim was to determine whether, and if so in what time, harmful constituents entering the reservoir at various points can reach the water supply inlet. The analysis has been conducted for a set of the points of origin of the pollutants and for various hydrometeorologic conditions, including a set of inflow and outflow discharge values, as well as a range of possible wind velocities.

Fig. 6 presents a graphical representation of a sample pilot particle tracking simulation within Dobczyce under the following conditions:

- The discharge values at the both primary and secondary inflows and outflows are close to their yearly averages.

- The wind impact can be neglected.

- The particles enter the reservoir with the primary inflow (the Raba River) and they are carried by the main current. 


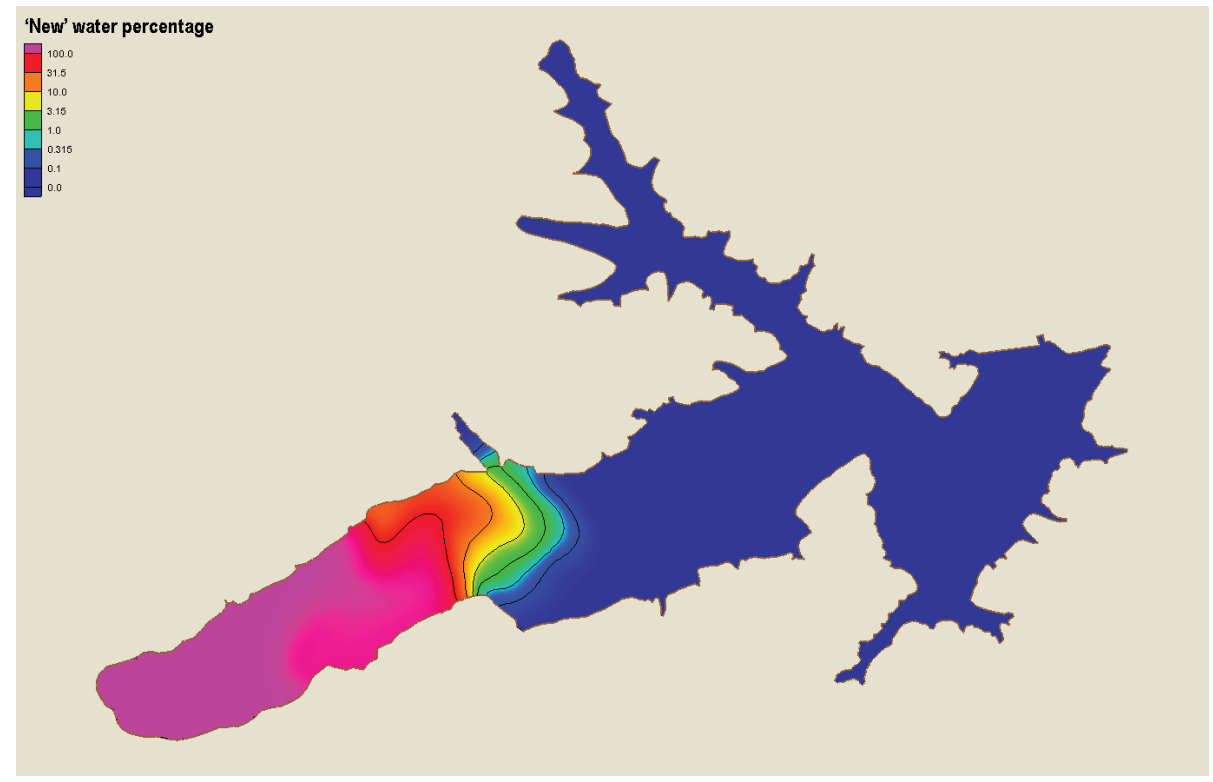

Fig. 7. Water exchange in Dobczyce Reservoir for the same hydrometeorologic conditions as per Fig. 6, but without introducing distinct currents and with dispersive processes taken into account; colors denote areas where newly Raba River-injected water appeared over a period of 2 weeks.

In these circumstances the particles reach the vicinity of the water supply inlet (indicated by an arrow on Fig. 6) in 65 to 75 hours, i.e., about 3 days. This is a much shorter time than one could expect not taking into account the presence of the current, but assuming a flow along the whole width of the reservoir bed crosssection instead. Fig. 7 shows how the water transport in the lake would look in the same circumstances if the currents were not present. "New" water injected by the Raba River (purple) replaces here the water previously present in the reservoir (dark blue). The figure presents

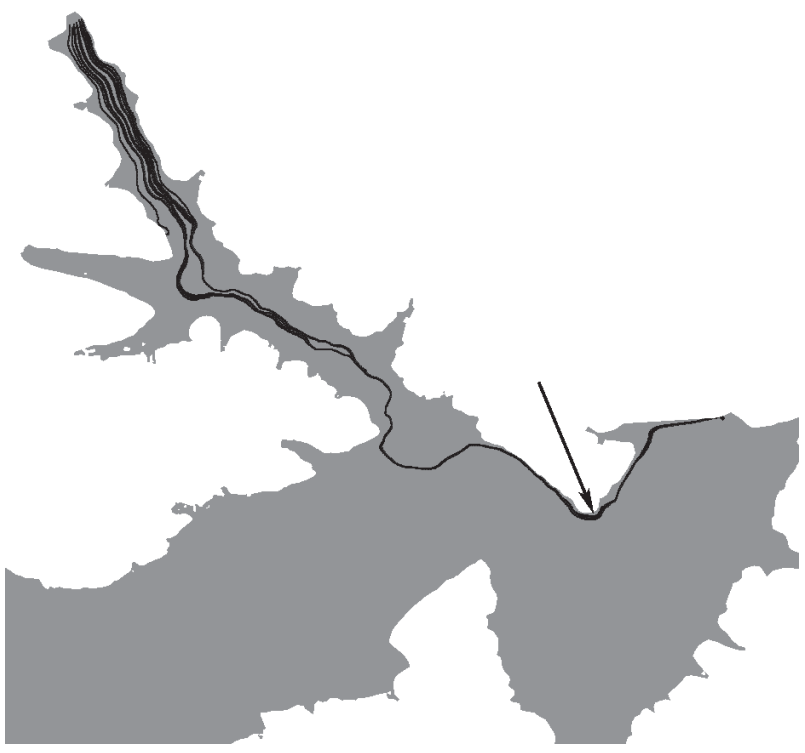

Fig. 8. Particle tracking for Dobczyce Reservoir from Wolnica Creek inlet to the dam outlet (average annual discharge, no wind); arrow denotes the position of the water supply inlet. the situation at the time of 2 weeks after the simulated flow started. One can observe 2 important effects here:

- The velocity is lower than before by more than an order of magnitude. This is because the whole bed cross-section is used to carry the discharge, while in the presence of a current most of the water remains stagnant.

- Mixing of "old" and "new" waters does occur (denoted by the color scale in Fig. 6.). The dispersive movement is slow, but it should be taken into account while building a transitory scenario: the more time a pilot particle needs to reach a certain location, the further from it real constituent particles may be due to the dispersion.

Another set of tracks of pilot particles in shown in Fig. 8. The hydrometeorologic conditions are the same as ones used to generate Fig. 6, but this time the pilot particles originate from Wolnica Creek. It takes them about 6 days to arrive in the vicinity of the water supply inlet. As shown in Fig. 8, the particles originating from Wolnica flow very close to the inlet, so any harmful constituent carried by the Wolnica into the reservoir may actually threaten the water supply in less than a week.

\section{Conclusions}

The assumptions, methods, and preliminary results described in this article seem useful and promising with respect to reach the specified goals. As for potential dynamic scenarios based on the water currents and uniform basins it can be said that the obtained result confirms that the methods of their construction and selection are generally correct. The main difficulty seems to be coupling the climate-related characteristics 
of the reservoir environment with the dynamic characteristics of the reservoir itself. The in-progress developmental process toward overcoming this obstacle includes:

- Finding direct dependencies between events and their rates of occurrence.

- Identifying and assessing indirect "fuzzy" relationships along with distinguishing their transitional forms and appropriate significance levels.

Active transitory scenarios of pollution transport based on particle tracking and diffusive dispersion were positively verified within the procedures of designing the "zone A" water supply protection area for Dobczyce Reservoir.

Generalizing the proposed methodology for wider use is under development. It depends on internal and external determinants of the considered reservoirs, along with spatial and temporal characteristics of the possible pollution events. Their unification on the hydrodynamic basis, containing both transitory and ecological potential scenarios, should provide a tool to improve the effectiveness of water protection-related tasks, including designing the protection zones, risk mitigation, and contingency plans. This wide-ranging approach to retaining and protecting water quality within reservoirs and their complex ecological potential requires multidisciplinary cooperation.

\section{Acknowledgements}

This work was conducted under the Institute of Water Engineering and Water Resource projects S1/200/2016/DS (Topic 5) and S1/194/2017/DS (Topic 5).

The data for Goczałkowice Reservoir were gathered within the strategic research project POIG 01.01.02-24078/09: "Integrated system supporting management and protection of dammed reservoir (ZiZoZap)."

\section{References}

1. STARMACH J., MAZURKIEWICZ-BOROŃ G. (ed.). The Dobczyce Reservoir: ecology - eutrophication protection, Zakład Biologii Wód PAN, Kraków 2010 [In Polish].

2. BOJARSKI A., GRĘLOWSKA Z., NACHLIK E. Long- and short-term usage of the Dobczyce Reservoir. Politechnika Krakowska, Krakow, 2012 [In Polish].
3. ATEREK E., BANDUŁA T., MATEREK E., MAZURKIEWICZ-BOROŃ G., SŁONKA R., SĄDAG T. (ed) The Dobczyce reservoir. Monografia. RZGW Kraków, Krakow 2016 [In Polish].

4. BOJARSKI A., GRĘPLOWSKA Z., NACHLIK E. (ed) The Goczałkowice Reservoir. A DPSIR analysis of processes and phenomena important for dammed reservoirs management. Politechnika Krakowska, Krakow, 2012 [In Polish].

5. AQUAVEO. SMS - The Complete Surface-water Solution. Available online: http://aquaveo.com/software/smssurface-water-modeling-system-introduction (accessed on 1206 2017).

6. FROELICH D.C. Two-Dimensional Depth-Averaged Flow and Sediment Transport Model. Federal highway administration, Mc Lean, Virginia 2003.

7. DONNELL B., KING I., MCANALLY W., THOMAS W. Users Gudie RMA2Version 4.5, Valhalla, New York, NY, 2009.

8. BERGER R.C., SAVANT G., MCALPIN T.O., TRAHAN C.J. Adaptive hydraulics users manual. AQUAVEO, Provo, UT, 2010.

9. WINTERS K. Adaptive hydraulics - 2D shallow water flow model interface within the surface-water modeling system. Brigham Young University, Provo, UT, 2008.

10. TRZEWIK M., Application of a FESWMS model on the Soła cascade reservoirs. Engineer degree thesis, Politechnika Krakowska, Kraków, 2011 [in Polish].

11. GAŁEK M., HACHAJ P.S. Application of the RMA2/ RMA4 Models to Simulate Pollution Transport in a Retention Reservoir, GeoPlanet: Earth and Planetary Science, Springer-Verlag, Berlin Heidelberg, 301, 2013.

12. WITEK K. Simulations of water flow in the Tresna reservoir using the ADH model. Engineer degree thesis, Politechnika Krakowska, Kraków, 2013 [In Polish].

13. HACHAJ P.S., TUTRO M. Flow patterns for dryling and wetting of a retention reservoir bed - numerical modeling. Infrastructure and Ecology of Rural Areas, 1407, 2014.

14. HACHAJ P.S., LEWICKI L., NACHLIK E., SIUTA T. Effectiveness of hydrodynamical models in simulation of dammed reservoir dynamics. Gospodarka Wodna, 286, 2014 [in Polish].

15. HACHAJ P.S., SZLAPA M. Impact of the thermocline on water dynamics reservoirs - Dobczyce Reservoir case. Archive of Mechanical Engineering LXVI (2), 189, 2017.

16. HACHAJ P.S. The "River Memory" effect - an attempt to understand and model it. In Experimental and Computational Solutions of Hydraulic Problems, SpringerVerlag, Berlin Heidelberg, 315, 2012. 
